\title{
Un gène candidat comme responsable de la neurofibromatose type 2 (NF2)
}

Le terme de neurofibromatose englobe deux maladies différentes, à transmission autosomique dominante, et entraînant toutes deux la formation de tumeurs, surtout dans lc système nerveux. La NF1 atteint une personne sur 4000 , son gène siège sur le chromosome 17 et a été récemment isolé et caractérisé $\left(\mathrm{m} / \mathrm{s} n^{\circ} 8\right.$, vol. 6, p. 815). La NF2 est dix fois moins fréquente, son symptôme principal est la présence de schwannomes qui se dévcloppent sur la branche vestibulaire du VIII'e ncrf crânien (neurinomes de l'acoustique). Le gène de la NF2 a été localisé sur le chromosome 22 en $1987\left(\mathrm{~m} / \mathrm{s} n^{\circ} 7\right.$, vol. 3, p. 424) et des travaux récents ont raffiné cette localisation en $22 \mathrm{~g} 12$. La perte fréquente d'un allèle sur le chromosome 22 dans des tumeurs sporadiques fait penser que le locus NF2 code pour un suppresseur récessif de tumeur. Une région candidate s'est peu à peu dégagée ; elle a révélé, chez quatre malades différents, qu'un gène porteur de délétions non chevauchantes pouvait être celui de NF2. Ce gène a été analysé par un consortium américain (Trofatter et al., 21 auteurs, dernier auteur J. Gusella) [1]. A partir d'une lignée lymphoblastoïde contenant une de ces délétions, on prépara des cosmides à son voisinage ; ils permirent, par la méthode d'amplification d'exons, d'obtenir 74 clones exoniques qu'on utilisa pour cribler des banques cérébrales. On put ainsi caractériser une phase ouverte de lecture dc 1761 bp codant pour une protéine de $69 \mathrm{kDa}$ comptant 587 acides aminćs. Le gène s'ćtend sur au moins $50 \mathrm{~kb}$. Le messager détecté par Northern blot montrait trois bandes, dcux majcures de 2,6 et $7 \mathrm{~kb}$, une mineure de $4,4 \mathrm{~kb}$. Il est présent dans la plupart des tissus humains et pas seulement dans le système nerveux.

La présence de délćtions non chevauchantes dans deux familles atteintes était déjà très démonstrative; les auteurs ont cherché d'autres altérations par SSCP (single strand conformational polymorphism) sur des ADNc amplifiés de sujets malades. Dcux tumeurs (sur cinq) montrèrent des images aberrantes, permettant, après analyse dćtaillće, de conclure à des délétions respectivement de 1 et de $4 \mathrm{pb}$, avec décalages de phase entraînant des terminaisons précoces. Il reste nécessaire, pour apporter la prcuve définitive qu'il s'agit bien d'un suppresseur de tumcur, de montrer que la réintroduction du gène supprime le développement de la tumeur.

Un des grands intérĉts de cette découverte tient à la nature de la protéine codée par ce gène qui présente en effet de fortes ressemblances avec d'autres protéines déjà connues, qui sont dans l'ensemble considérćes comme des maillons unissant la membrane cellulaire et le cytosquelette. Ces protéines conticnnent toutes trois domaines : un domaine N-terminal d'environ 200 à 300 acides aminćs, où les homologics sont les plus marquées; un segment central en hćlice, et une partie Cterminale porteuse de nombreuses charges. Au cours de l'évolution leur conservation est trc̀s grande, on en retrouve des traces dans plusieurs espèces d'annélides. Trois de ces protéines sont particulièrement proches : il s'agit dc la moesine [2] (membrane organizing extension spike protein), de l'ezrine [3], appelée aussi cytovilline [4] et de la radixine [5]. Leur degré d'homologie avec la protéine NF2 attcint $50 \%$, et bien davantage dans la partie $\mathrm{N}$ - terminalc. Le consortium propose [1] dc donner de cette nouvelle protéine le nom de merline (pour meesin-eznin-radixin like). D'autres ressemblances, plus lointaines, avec des protéines de membranes ou d'adhérence ont été signalées, notamment avec la protéine dite 4.1, ct la taline, protéine de plus grande taille qu'on trouve dans les zones d'adhérence intercellulairc [6]. La similarité de la merline avec ces protéines laisse prévoir pour elle un rôle d'intermćdiaire cntre cytosquclette et membranes cellulaires. Il reste à comprendre comment ce rôle supposé peut expliquer la fonction de suppresseur de tumeur que suggère la pathologie. Il faudra donc imaginer et explorer des voies nouvelles pour aborder ce problème pour lequel n'existent actuellcment que des hypothèses sans support expćrimental.

J.C.D.

1. Trofatier JA, Mac Collin M, Rutter JL, et al. A novel moesin-ezrin-radixin like gene is a candidate for the neurofibromatosis 2 tumor suppressor. Cell 1993; 72 : 791-800.

2. Lankes WT, Furthmayr H. Moesin : a member of the protein 4.1-talin family of proteins. Proc Natl Acad Sci USA 1991; 88 : 8297-301.

3. Gould KI, Bretscher A, Esch FS, Bunter T.cDna cloning and sequencing of the proteintyrosine kinase substrate czrin ; reveals homology to band 4.1. EMBO J 1989; $8: 4133-42$. 4. Turunen $O$, Winqvist $R$, Pakkanen R, Grzeschik $\mathrm{KH}$, Wahlstrom T, Vaheri A. Cytovillin, a microvillar Mr 7500 protein. cDNA sequence, procaryotic expression, and chromosomal localization. J Biol Chem 1989; 264: 16727-32.

5. Sato N, Yonemura S, Obinata T, Tsukita S, Tsukita S. Radixin, a barbed end-capping actinmodulating protein, is concentrated at the eleavage furrow during cytokinesis. J Cell Biol 1991; $113: 321-30$

6. Rees DIG, Ades SL, Singer SJ, Hynes RO. Scquence and domain structure of talin. Nature $1990 ; 343: 685-9$. 